\title{
Evolution of the incisal relationship in a Central European population (1870/1970)
}

\author{
O. Laplanche ${ }^{1}$, J.-D. Orthlieb ${ }^{3}$, M. Laurent ${ }^{3}$, O. Vyslozil ${ }^{2}$, O. Dutour ${ }^{4,5}$ \\ ${ }^{1}$ Faculté d’Odontologie Université de Nice-Sophia Antipolis, Nice, France \\ ${ }^{2}$ Faculté d'Odontologie de Marseille, Université de la Méditerranée, Marseille, France \\ ${ }^{3}$ Faculté d'Odontologie de Vienne, Vienna, Austria \\ ${ }^{4}$ Faculté de Médecine de Marseille, Université de la Méditerranée, UMR 6578 CNRS-EFS-Aix Marseille Université, \\ Marseille, France \\ ${ }^{5}$ Department of Anthropology, University of Toronto, Toronto, Canada
}

Received October 13, 2009; Accepted January 25, 2010

Recent studies have supported the hypothesis that there is a tendency to evolution in the occlusal relationships of urban populations. Due to its role in the stomatognathic system and the hypothesis of the role of deep overbite in the appearance and development of TMD, particular interest is given to the incisal relationship and its evolution in urban populations.

Incisal situation and relationship can be studied with anthropometric and cephalomatric determinants.

This study compares the incisal relationship of two groups of young Caucasian adults born in 1870 and 1970, respectively.

Twenty-four anthropometric and cephalometric points were analyzed for 30 subjects from each group. A statistically significant difference between the 1870/1970 samples was found for the following criteria $(p<0.001)$ : overbite: 1.17/ 3.81 , position of the free edge of the mandibular incisor, sagittal values (orthodontic norm PAO) $78.75 \mathrm{~mm} / 82.88 \mathrm{~mm}$, position of the free edge of the mandibular incisor, vertical values $54.74 \mathrm{~mm} / 58.87 \mathrm{~mm}$, FMIA angle: $65.97^{\circ} / 58.4^{\circ}$ and Angle classes: difference in distribution of the skeletal classes (Classes I, II and III) between the two populations (increase in Class II, 1970).

Within the limits of this study results show a remarkable increase in overbite, a tendency towards a reduced prevalence of class III malocclusions and an increased prevalence of Class II malocclusions with vestibular position of the mandibular incisors.

Keywords: Occlusion, incisor, anterior guidance, overbite, overjet, craniofacial évolution, anthropology

Correspondence: Olivier Laplanche, Faculté d'Odontologie, Université de Nice-Sophia Antipolis, 24 Avenue des Diables bleus, 06000 Nice, France. E-mail: olivier.laplanche@unice.fr

\section{Introduction}

The relationship between the maxillary and mandibular incisors is one of the keys to occlusal organization according to Ackerman [1] and Mc Horris [27]. Incisors play an important role in the occlusal functions, providing mandibular stability and guidance and are essential for the physiological function of the stomatognathic system [39-21]. The role of the incisors is often referred to as the anterior guidance.

Abnormalities of anterior guidance have been considered as risk factors for oral dysfunction due to:

Mechanical demands placed on other teeth by occlusal interferences [24-18].

Altered mandibular movement to avoid interferences causing Strain to muscles and ligaments [29-38]. Resulting muscular hyperactivity [38-4].

Clinical observations of human skulls from different periods $(-2000 \mathrm{BP} / 1900)$ and phylogenetic analysis of the incisal relationship (and of occlusion) suggest, however, that anterior guidance is a recent phenomenon [9]. Anterior guidance seems to have appeared recently and rapidly over the 20th century, in combination with an increase in the prevalence of malocclusion [36] and dental Class II malocclusion particularly in recent generations.

Vizlozyl et al. stated that significant differences exist between two groups of subjects born in 1870 and 1970 in terms of tooth width, prevalence of Class II malocclusion, dental crowding and certain others parameters of dental occlusion [36]. The theory of recent, rapid evolution of the anterior occlusal scheme may thus be upheld.

The study presented here is a re-examination of the data used by Vizlozyl et al. relating to the evolution of incisor guidance, as traced in these two populations from 1870 and 1970 [22].

The aim of the study was to investigate the incisal relationship, regarding occlusal and cephalometric markers, of two equivalent populations of young Western European males born in 1870 and 1970 (a diachronic study) and to find whether 
any significant differences exist between the incisal relationship of these two populations using cephalometric and anthropometric criteria.

\section{Materials and methods}

\section{Materials}

The study used material from the Dental Faculty and from the Museum of Natural History, Vienna, Austria, previously gathered by Vyslozyl et al. [36]. The material consisted of a series of orthopantomograms, dental casts and dental records of two groups of subjects:

The 1870 group (Gr. 1870) data were from 133 male skulls of soldiers who had served in the Austro-Hungarian Army. They were all born about 1870 and died of disease at around 25 years of age (the skulls form part of the Weisbach collection, Vienna, Austria).

The 1970 group (Gr. 1970) was made up of data taken from 170 male conscripts to the Austrian Federal Army born about 1970, in the same region as the previous group, and of an average of 20 years at the time of study.

Thirty subjects were chosen at random from the each of the two groups.
The two groups are from the same ethnic origin, about 25 years of age and were evaluated with the same occlusal relationship.

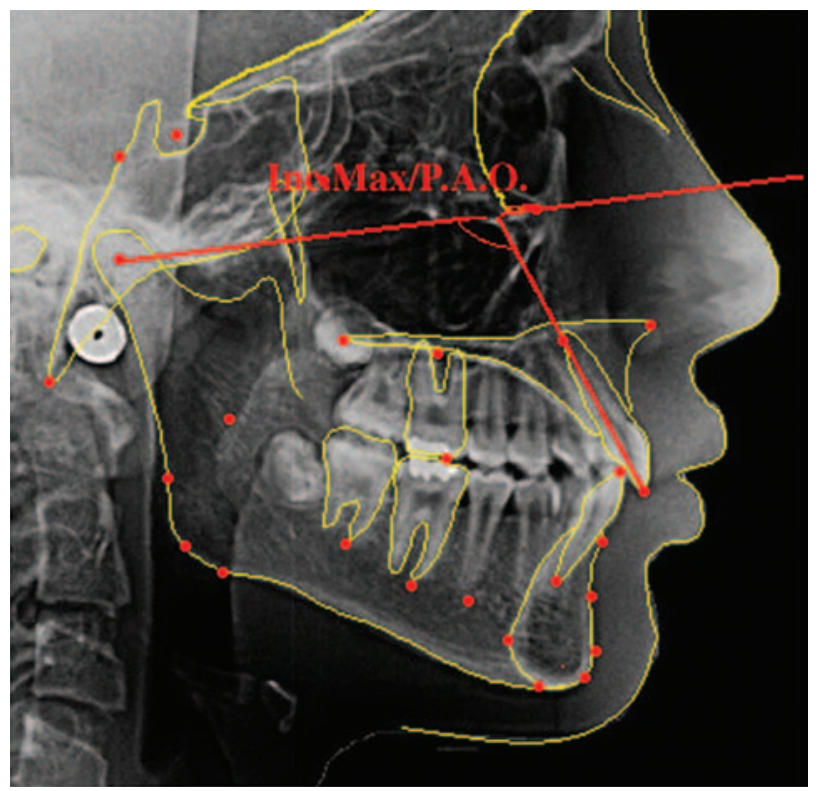

Fig. 1: Teleprofile radiograph and cephalometric analysis

\section{Tab. 1: List of cephalometric value analysed}

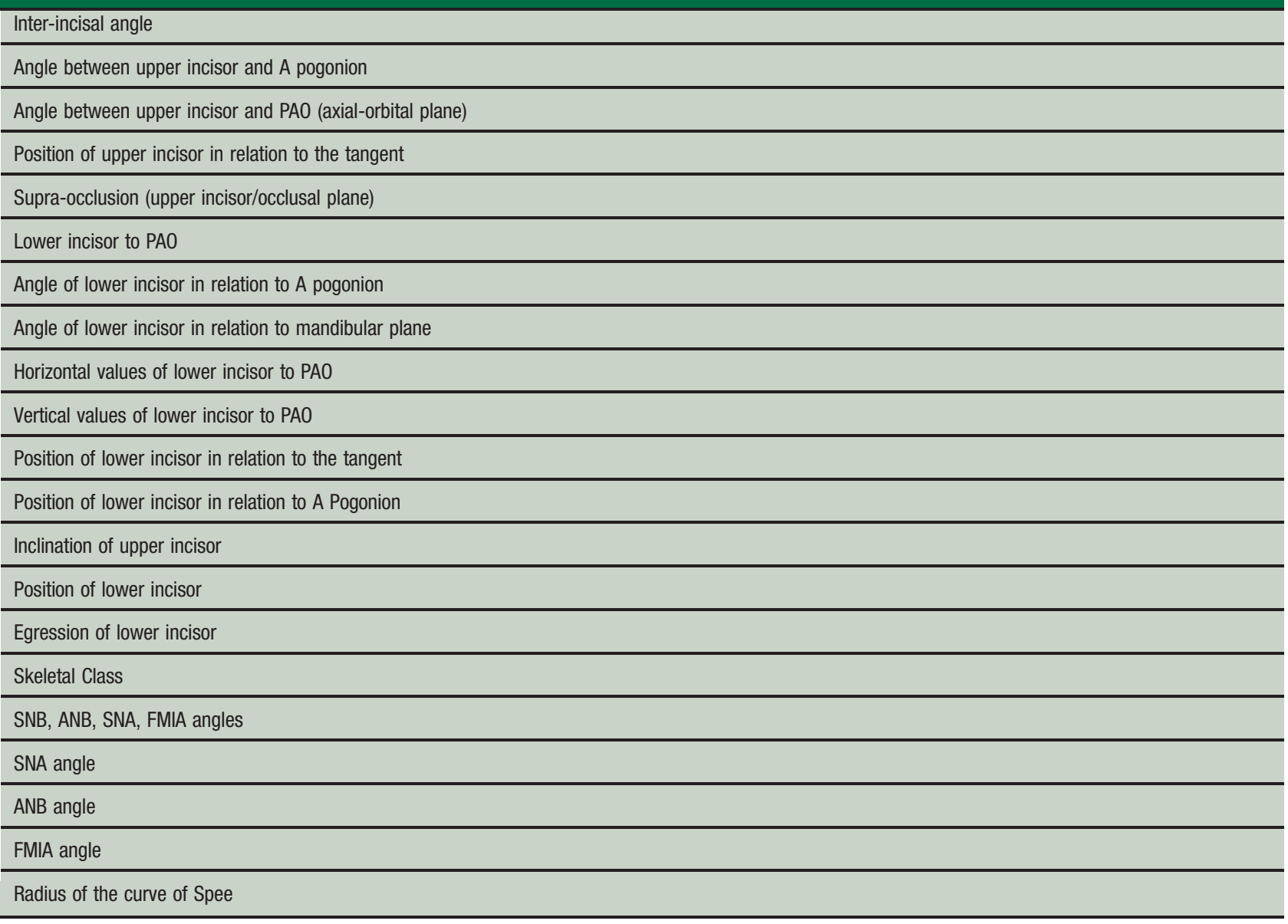




\section{original article}
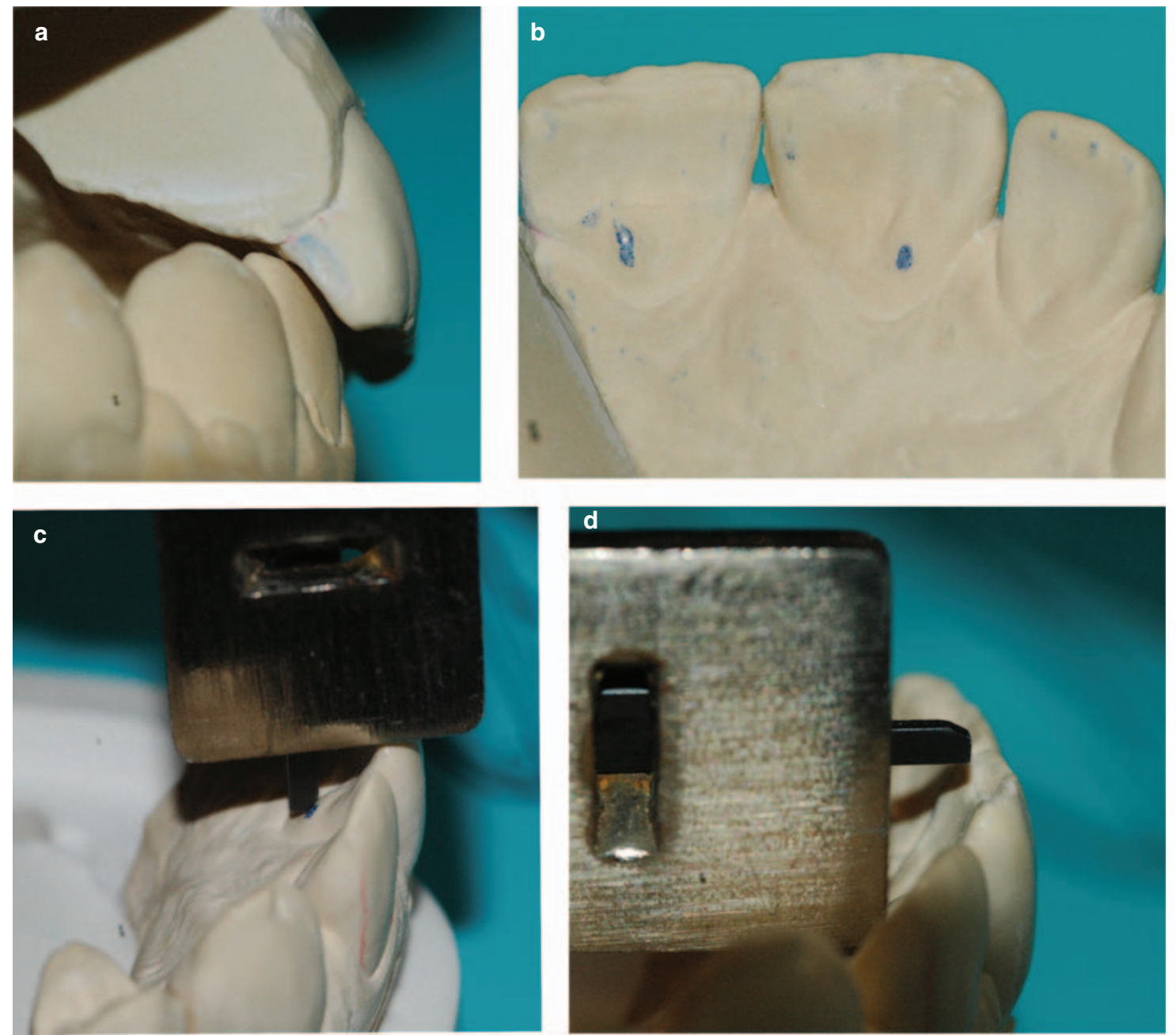

Fig. 2: Determining overbite and overjet from models in centric occlusion (a); occlusal mark in centric occlusion (b); overbite evaluation (c) and overjet evaluation (d)

The following material was used for the cephalometric analysis:

A standard cephalometric teleprofile radiograph, taken at three meters distance.

A cephalometric tracing ( $3 \mathrm{M}^{\circledR}$ paper) using fine markers (Stabilo, OHP, 841).

CADO software for cephalometric analysis.

Dental analysis was performed using maxillary and mandibular plaster models and digital calipers.

\section{Method}

A cephalometric tracing was made of each teleprofile radiograph and the 52 points needed for computer analysis were marked (Fig. 1). These data were scanned and computer analysis was performed. Multiple values (angles and distances) for the incisal relationship were retained (Table 1).

The maxillary and mandibular models were placed manually into maximal intercuspidation and the values for sagittal and vertical overbite of the upper right medial incisor and antagonist were measured (Fig. 2).

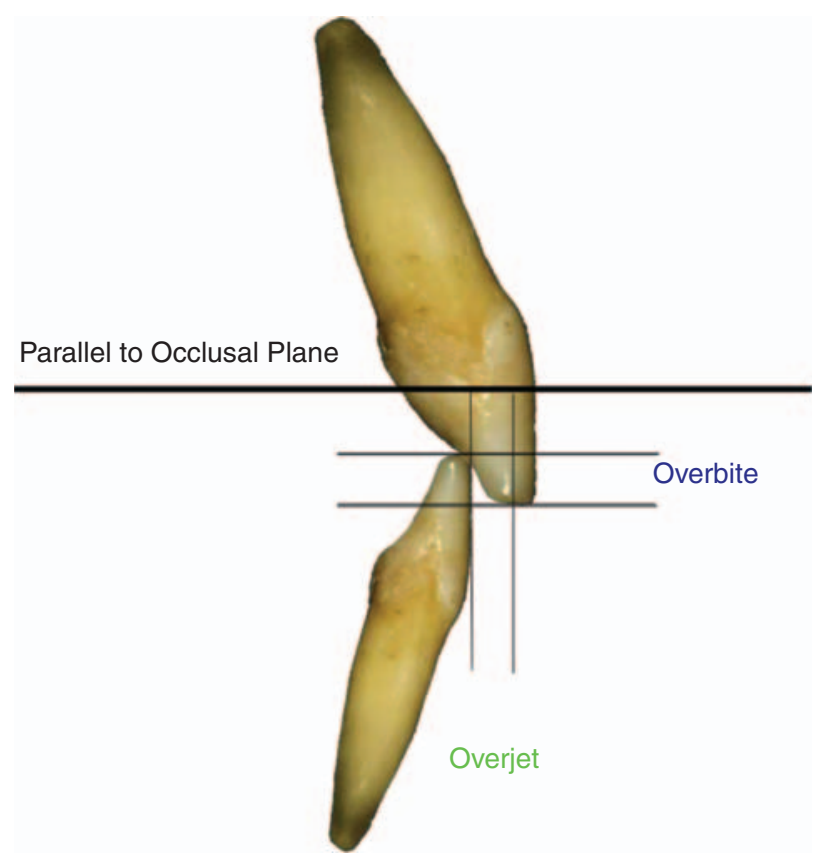

Fig. 3: Overjet and overbite evaluation in reference to occlusal plane 
Vertical overbite was measured by marking the occlusal contact point between the lower incisor and the palatal surface of the upper incisor and measuring the vertical distance (perpendicular to the occlusal plane) between this point and the free edge of the upper incisor. If the upper and lower incisors did not have any contact, a mark was made on the palatal surface of the upper incisor exactly horizontal to the free edge of the lower tooth using a pencil. The value was positive in the caudal direction and negative in the cranial direction.
Overjet was measured by placing the free end of the calipers against the vestibular surface of the lower incisor and the base of the calipers against the lingual surface of the free edge of the upper incisor. Positive values were related to the anterior direction and negative values to the posterior direction.

For overbite and overjet evaluation, calipers were placed parallel to the occlusal plane, used as a reference (Fig. 3).

\section{Tab. 2: Results summary}

\begin{tabular}{|c|c|c|c|c|c|c|c|c|}
\hline & \multicolumn{3}{|c|}{ Gr. 1870} & \multicolumn{3}{|c|}{ Gr. 1970} & \multicolumn{2}{|c|}{ Comparaison } \\
\hline & Mean & Variance & $\begin{array}{l}\text { Standard } \\
\text { deviation }\end{array}$ & Mean & Variance & Ecart Type & t Test & $\begin{array}{l}\text { Significance } \\
(p<0.001)\end{array}$ \\
\hline Skel. Class. & \multicolumn{2}{|c|}{ cf tableau de contingence } & & & & & & \\
\hline SNB & 81,33 & 19,90 & 4,46 & 79,92 & 30,31 & 5,51 & 1,07 & NS \\
\hline ANB & 1,63 & 6,70 & 2,59 & 1,21 & 14,50 & 3,81 & 0,50 & NS \\
\hline SNA & 82,96 & 25,77 & 5,08 & 81,13 & 21,66 & 4,65 & 1,43 & NS \\
\hline FMIA & 65,97 & 79,70 & 8,93 & 58,40 & 61,67 & 7,85 & 3,43 & significatif \\
\hline \multirow[t]{3}{*}{ Rayon Spee } & 90,41 & 973,83 & 31,21 & 74,84 & 1443,24 & 37,99 & 1,71 & NS \\
\hline & \multicolumn{3}{|c|}{ Gr. 1870} & \multicolumn{3}{|c|}{ Gr. 1870} & & \\
\hline & Mean & Variance & $\begin{array}{l}\text { Standard } \\
\text { deviation }\end{array}$ & Mean & Variance & Ecart Type & t Test & $\begin{array}{l}\text { Significanice } \\
(p<0.001)\end{array}$ \\
\hline \multicolumn{9}{|l|}{ Gr. 1870} \\
\hline Vertical Overbite & 1,17 & 3,88 & 1,97 & 3,81 & 2,10 & 1,45 & 5,82 & Significatif \\
\hline Sagittal Overbite & 2,24 & 1,92 & 1,39 & 2,46 & 0,84 & 0,92 & 0,72 & NS \\
\hline \multirow[t]{3}{*}{ Inter-incisal angle } & 138,74 & 86,99 & 9,33 & 135,42 & 78,88 & 8,88 & 1,39 & NS \\
\hline & \multicolumn{3}{|c|}{ Gr. 1870} & \multicolumn{3}{|c|}{ Gr. 1870} & & \\
\hline & Mean & Variance & $\begin{array}{l}\text { Standard } \\
\text { deviation }\end{array}$ & Mean & Variance & Ecart Type & t Test & $\begin{array}{l}\text { Significance } \\
(p<0.001)\end{array}$ \\
\hline \multicolumn{9}{|l|}{ Upper Incisor } \\
\hline \multicolumn{9}{|c|}{ Angle between upper incisor and } \\
\hline A-pogonion & 18,29 & 20,59 & 4,54 & 21,11 & 58,50 & 7,65 & 1,71 & NS \\
\hline \multicolumn{9}{|c|}{ Angle between upper incisor and } \\
\hline PAO (axial-orbital plane) & 102,59 & 39,05 & 6,25 & 102,18 & 62,67 & 7,92 & 0,22 & NS \\
\hline Imaxpos/ Apog & 4,69 & 6,32 & 2,51 & 5,46 & 9,83 & 3,13 & 1,03 & NS \\
\hline Inclinaison & $-2,87$ & 15,25 & 3,90 & $-1,82$ & 35,64 & 5,97 & 0,79 & NS \\
\hline Position & $-0,79$ & 9,69 & 3,11 & $-0,04$ & 7,99 & 2,83 & 0,97 & NS \\
\hline \multicolumn{9}{|c|}{ Supra-occlusion (upper incisor / } \\
\hline occlusal plane) & $-4,79$ & 5,16 & 2,27 & $-0,95$ & 4,08 & 2,02 & 6,80 & significatif \\
\hline \multicolumn{9}{|l|}{ Lower Incisor } \\
\hline I Mand / Pao & 61,31 & 74,98 & 8,66 & 57,62 & 66,29 & 8,14 & 1,67 & NS \\
\hline \multicolumn{9}{|c|}{ Angle of lower incisor in relation } \\
\hline to A pogonion & 22,96 & 39,49 & 6,28 & 22,41 & 18,76 & 4,33 & 0,39 & NS \\
\hline \multicolumn{9}{|c|}{ Angle of lower incisor in relation } \\
\hline to mandibular plane & 91,09 & 66,85 & 8,18 & 89,64 & 77,91 & 8,83 & 0,65 & NS \\
\hline \multicolumn{9}{|l|}{ Horizontal values of lower } \\
\hline incisor to PAO & 78,75 & 42,76 & 6,54 & 82,88 & 45,74 & 6,76 & 2,37 & significatif \\
\hline \multicolumn{9}{|c|}{ Vertical values of lower incisor } \\
\hline to PAO & 54,74 & 33,85 & 5,82 & 58,87 & 67,41 & 8,21 & 2,21 & significatif \\
\hline \multicolumn{9}{|l|}{ Position of lower incisor in } \\
\hline relation to the tangent & $-5,63$ & 78,07 & 8,84 & $-3,48$ & 53,90 & 7,34 & 1,01 & NS \\
\hline \multicolumn{9}{|l|}{ Position of lower incisor in } \\
\hline relation to A Pogonion, & 0,69 & 10,01 & 3,16 & 1,23 & 13,32 & 3,65 & 0,59 & NS \\
\hline Inclination & $-1,15$ & 54,73 & 7,40 & $-1,89$ & 18,90 & 4,35 & 0,46 & NS \\
\hline Position & $-0,27$ & 7,47 & 2,73 & $-0,18$ & 12,87 & 3,59 & 0,10 & NS \\
\hline Egression & 0,95 & 7,84 & 2,80 & $-4,43$ & 12,57 & 3,55 & 6,42 & significatif \\
\hline
\end{tabular}




\section{Statistical analysis}

\section{Method validation}

Prior to evaluating the entire sample, the validity of the method was tested. One case was selected at random from the sixty test cases and measurements were repeated ten times by the investigator. Then the observed values were compared to assess reproducibility of the cephalometric and anthropometric techniques. The variation in the anthropometric values was $0.2 \mathrm{~mm}$ (overbite and overjet) and 0.8 degrees for the cephalometric values.

\section{Comparison of the two populations}

The values were collected and statistical analysis was undertaken using StatView software. The cephalometric and occlusal data of the two populations were compared using parametric tests for large sample sizes and the distribution of skeletal class was determined using the Chi-squared test.

\section{Results}

Anthropometric evaluation (Table 2)

Vertical overbite: mean value for Gr. 1870: 1.17 (SD: 1.97) and Gr. 1970: 3.81 (SD: 1.45).

There is a highly significant difference between the two groups $(p<0.001)$.
Sagittal overbite: No statistically significant difference $(p<0.001)$ was found for values of sagittal overbite between the two populations.

\section{Cephalometric evaluation}

A statistically significant difference was found for the following variables:

Position of the free edge of the mandibular incisor, sagittal values $(p<0.001)$ (Figs. 4, 5).

$$
\begin{aligned}
& \text { Gr. 1870: } 78.75 \mathrm{~mm} \text { (SD: 6.54) } \\
& \text { Gr. 1970: } 82.88 \mathrm{~mm} \text { (SD: 6.76) }
\end{aligned}
$$

Position of the free edge of the mandibular incisor, vertical values $(p<0.001)$ (Figs. 4,5$)$.

$$
\text { Gr. 1870: } 54.74 \mathrm{~mm} \text { (SD: 5.82) }
$$

Gr. 1970: $58.87 \mathrm{~mm}$ (SD: 8.21)

The FMIA angle $(p<0.001)$ (Fig. 6).

$$
\begin{aligned}
& \text { Gr. 1870: } 65.97^{\circ} \text { (SD: 8.83) } \\
& \text { Gr. 1970: } 58.40^{\circ} \text { (SD: 7.85) }
\end{aligned}
$$

\section{Skeletal class}

There was a statistically significant difference between the distribution of the different skeletal classes (Classes I, II and

\section{Tab. 3: Repartition between skeletal class in Gr. 1870 and Gr. 1970}

\section{Repartition between Skeletal class in Gr. 1870 (grey) and in Gr. 1970 (blue)}
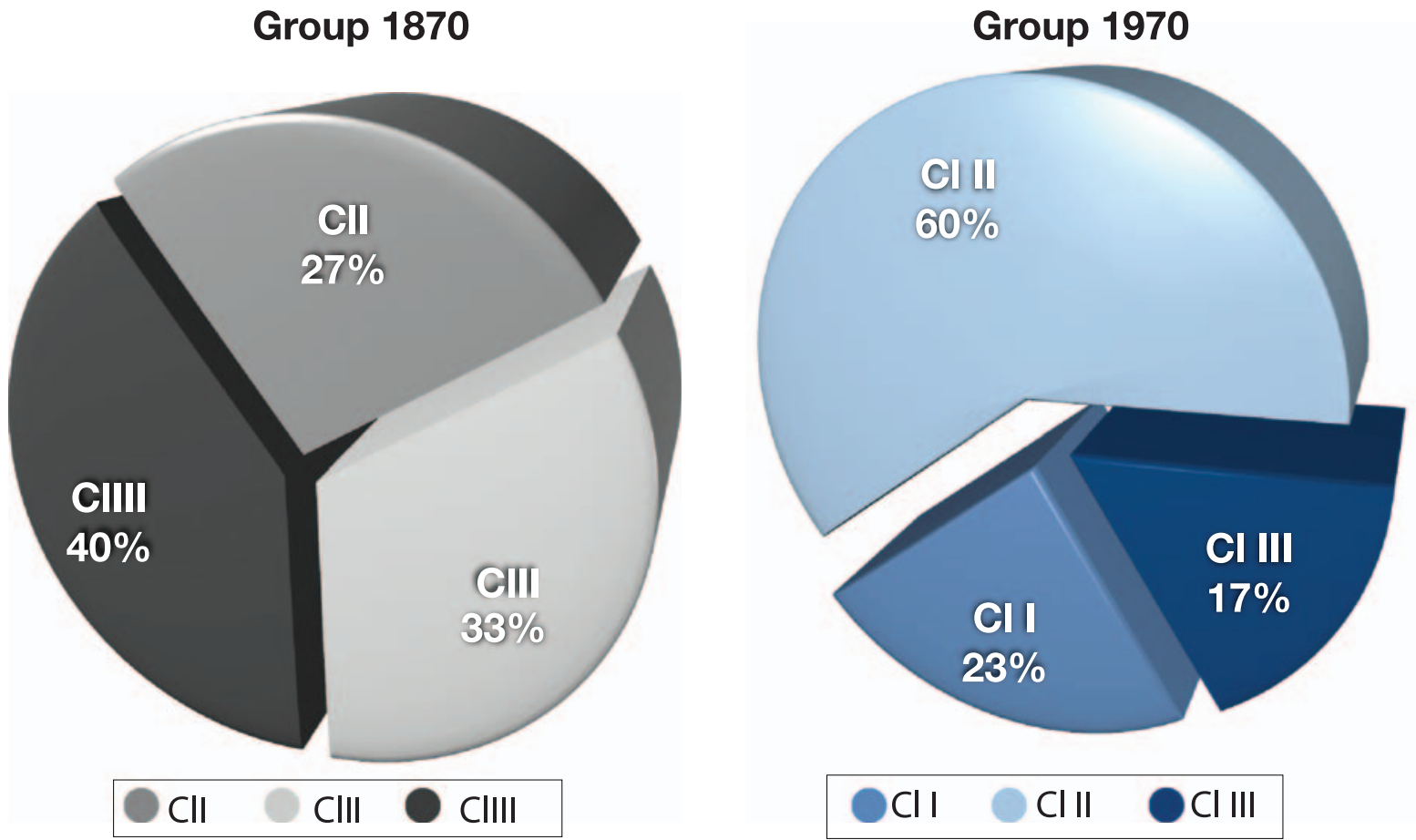
III) between the 1870 and 1970 groups using the Chi-squared test $(p<0.01)$.

\section{Summary of results}

Significant differences were found for the 1970 population compared to the 1870 group for the following:

Value for overbite were greater.

The position of the mandibular incisor in relation to the PAO (sagittal and vertical values) was increased along the line incision-ptO.

FMIA angle showed a tendency to vestibularization of the mandibular incisor.

Higher prevalence of skeletal Class II.

Thus the overall tendency amongst this population of young Western European males was to mandibular retrusion, vestibularization of the mandibular incisors and caudalization of the maxillary and mandibular incisors.

\section{Discussion}

These results confirm the findings of other studies that have shown alteration in the skeletal and occlusal patterns over recent generations [36-15]. The appearance of the notion of vertical overbite over the last few hundred years is also confirmed. In accordance to a previous literature review [22] the following theories are upheld by the present data:

Differences in occlusal patterns are found between populations, according to lifestyle and feeding habits. On studying the prevalence of malocclusion, it has been suggested that human dentition has undergone more changes within the last 200 years than during the previous 6000 years [31-2]. These differences have also been noted amongst the primates and some other mammals but are most marked amongst humans (10-100 times more frequent according to Andrik [3] and Ernst [12]. Compare traditional to urban populations, an epidemiological study noted a higher prevalence of malocclusion related to the degree of urbanization [7]. The degree of muscular force provided by the masticatory muscles was also found to be decreased in urban children compared to their peers of the same ethnic origin, living in rural conditions. The etiology of these changes has been assumed to be environmental rather than genetic.

It seems, however, that one of the main factors for the alteration of the occlusal scheme is the changing shape of the upper arch and an ongoing reduction of the maxillary size over generations. Newborn babies of today tend to have a narrow, vaulted palate that may be related to a reduction in size of the maxilla compared to prehistoric times [37]. This theory has been supported by other authors, who think that the increasing prevalence in malocclusion is related to the size of the maxilla and may be associated with respiratory difficulties [25-32]. A connection has been made between this hypothesis and problems of pollution and lingual posture [14].

\section{Simultaneous evolution of stature and cranio-facial morphology}

Changes in the cranial skeleton can be related to general evolution in posture and to alterations in cranial morphol- ogy from one generation to the next (secular acceleration) [13].

Secular acceleration might act parallel with the leptomorphic tendency to cause the changes observed in cranial growth over recent generations [37]. The hypothesis of a correlation between secular acceleration and anterior crowding has been supported by the work of Holly Smith et coll [16] and Van der Linde [35]. These authors suggest that the face is becoming longer and thinner over generations. Supporting this theory, facial dimensions have been shown to be undergoing measurable changes [10]. Most authors agree that this is an evolutionary trend towards Class II malocclusion [15]. This finding is most clearly demonstrated in the industrialized populations, which underlines the influence of lifestyle and environmental factors.

\section{Cranio-facial evolution is of mixed etiology}

It has been suggested that hereditary factors may be the most important aspects of facial growth and adult appearance, and that tooth morphology and the chondrocranium may be considered to be under genetic control. The genetic factors are, however, subordinated during secondary growth of the facial skeleton, which depends on the development of the surrounding tissues under the influence of oro-facial function [35].

The development of oro-facial function is altered by external or environmental factors, which thus must have considerable influence on facial growth. In support of this mixed hypothesis, several authors have related the clinical findings of cross bite, open bite and endognathia to mouthbreathing and reduced masticatory and oral function [25-10].

\section{Cranio-facial evolution influences occlusal patterns}

A study of the occlusion of primitive populations has shown worn dentition without anterior guidance and with marked attrition of the cuspid. This type of occlusion has been found both in the medieval population in the south of France and in the plague victims of Marseille, France from 1720 [20]. Considering the anterior dentition, studies of Aborigines, isolated for the last 6000 years, show a clear tendency to a reduction of the incisal overbite in adults and a very slight tendency to a reduction of overjet [5]. These results have been confirmed in other groups and have led to the theory that an anterior edge relationship resulting from wear may be considered as a characteristic of primitive populations [6].

Group function has also been identified as typical in the Aboriginal population [9]. Non-working side contacts have not been found in this population but working side contacts are numerous for all ages. This is considered to be due to extensive wear of the anterior sector from an early age on and stands in contrary to findings in equivalent European populations.

The study of a young adult population presented in this article shows, however, that the position of the anterior teeth before wear does not allow posterior contact to be avoided. Therefore abrasion and attrition cannot be made responsible entirely for this occlusal pattern.

Group function is consistently found in the worn dentition of American Indians prior to colonization and in the 
Aborigines [8]. In the Aboriginal population it has even been shown that all lateral teeth, are part of the group function including the canines [9]. Wear was thought to be even greater in the prehistoric populations, although it varied according to tooth type, the individual, the observed population and the age of the subject (greater wear over 30 years of age) [5]. The uniformity of wear suggests in all cases that anterior guidance did not exist.

The incisal guiding must thus be of recent origin, a fact supported by the lack of overbite found in studies relating to recent periods of history, for example, in the study by Lacroix and Laurent [20] of plague victims from 1720 in the south of France. Some authors feel that anterior guidance started to appear in the Middle Ages as the use of the fork became widespread. Another example of relatively recent change is a study of the Maïdu Indians from California. This population showed much worn dentition (with severe wear of the occlusal surfaces and an incisal edge relationship (labiodontia) up to colonization. Later studies show that occlusion had changed to include the incisal overbite, a "locking" canine occlusion and a curve of Spee, similar to that of the white population [23]. These changes were presumably due to alteration of the diet.

Evidence is strong in favour of the theory that dentition evolves by functional adaptation to different lifestyles and diets. Modern man living in an industrialized nation no longer uses his anterior teeth as a tool and does not need them to be in an edge to edge relationship functionally. Masticatory forces no longer oppose the eruption of the incisors, and so supraocclusion may result.

In the same way, softer, more prefabricated diet reduces the masticatory forces needed for comminuting and reduces abrasive wear of the teeth. These factors have an effect from the earliest age, particularly if an infant is not breastfed. The development of masticatory forces is altered and lingual propulsion and sagittal growth are stimulated.

\section{Conclusion}

Within the limitation of this study the results suggest a significant difference in overbite and its skeletal determinant (skeletal class, mandibular incisal position/PAO, FMIA angle).

To resume, two principal axes can be identified to explain this evolutionary phenomenon.

General evolution of the species: Phylogenetic studies of the Homo species show that bipedia, cerebralization and right hand dominance are associated with the considerable amount of alveolar bone reduction. These changes represent the evolution of our species from a mechanical point of view (poor proprioception, strong muscular force, strong bony structures in relation to the force exerted), to a biomechanical model (accurate proprioception, reduced muscular force and reduced supporting structures). This refining of facial morphology has taken place over the last several hundred million years.

Specific evolution of the masticatory apparatus has taken place in response to functional adaptation to a new social environment, and is represented by Slavicek's cybernetic concept (1983) [33]. This "micro-evolution" shows the tendency for an increasing prevalence of Class II malocclu- sion, mandibular retrognathy and an increased anterior overbite.

The definition of these evolutionary concepts is the first step in anthropological analysis of the different types of occlusion and in the definition of what we have considered as a "normal" occlusion, serving as a basis for dental diagnosis and treatment.

\section{Conflict of interest}

The authors declare that there is no conflict of interest.

\section{References}

[1] O. Akermann F. Le mécanisme des machoires Masson et Cie (Paris) 1953.

[2] Andrick P. Vorkommen der Geùbi Bibanomalien in der Welt. Anthropol Bratislava 1971;16:9-18.

[3] AndrickP. Die Entwicklung der Bibanomalien vo, neolithikum bis zur Gegenwart Fortschr Kieferorthop 1963;24:12-21.

[4] Ash MM. Occlusion: Reflections on science and clinical reality. J Prosthet Dent 2003;90:373-84.

[5] Beyron H. Occlusal relation and mastication in australian aborigines. Acta Odontologica Scandinavica 1964;6:598-678.

[6] Brabant H. L'évolution de l'appareil masticateur humain, du paléolithique à nos jours. Odontostomatologique du nord de la France 1964;334:232-5.

[7] Coruccini RS. Bite force variations related to occlusal variation in rural and urban Punjabis. Arch Oral Biol 1985;30:65-9.

[8] D'Amico A. Application of the concept of functional relation of the natural teeth of the man. J S Calif Dent Ass 1959;27:39.

[9] D'Amico A. The canine teeth. Normal functional relation of the natural teeth of man. J S Calif Dent Ass 1958;6-23.

[10] Dausch Neumann D. cité dans Kenntner Die Veränderung der Köpergrösse des Menschen Dissertationsschrift, Universität des Saarlandes, Karlsruhe 1963.

[11] Dos Santos J Jr, Blackman RB, Nelson SJ. Vectorial analysis of the static equilibrium of forces generated in the mandible in centric occlusion, group function, and balanced occlusion relationships. Journal of Prosthetic Dentistry 1991;65:(4):557-67.

[12] Ernst T, Inke G. Die BiBlagen und Stellundgsanomalien beim Affen im Vergleich zur mensclichen Pathologie. Fortschr Kieferorthop 1966;2:247-53.

[13] Gaspard M. Essai d'analyse biomécanique comparative de la mastication chez les carnivores les anthropoïdes et l'homme Revue d'Odonto. Stomatologie 1967;85-108.

[14] Gola R. Report of the International congress of Collège National d'Occlusodontie Reims. CNO edition Paris 2001.

[15] Guichard P, Mafart B, Orthlieb JD. Comparison of occlusion in medieval and present-day populations in southeast France. Am J Orthod Dentofacial Orthop 2001;120(6):585-7.

[16] Holly Smith B. et coll. Säkulare Trends der Gesischtsdimensionen. Inf Irthod Kieferorthop 1991;23:153-66.

[17] Huang BY, Whittle T, Peck CC, Murray GM. Ipsilateral interferences and working-side condylar movements. Arch Oral Biol 2006;51:206-14

[18] Ingervall $B$. Tooth contacts on the functional and non-functional side in children and young adults. Arch Oral Biol 1972;17:191-5.

[19] Ishigaki S, Kurozumi T, Morishige E, Yatani H. Occlusal interference during mastication can cause pathological tooth mobility. J Periodont Res 2006;41:189-92.

[20] Lacroix P, Laurent M, Laplanche O. Le surplomb et le recouvrement incisif dans l'évolution du guide antérieur Info. Dent 2000;40:3473-8.

[21] Laplanche O, Pédeutour P, Laurent M, Mahler P, Orthlieb JD. Le guide antérieur et ses anomalies, incidence sur la cinématique condylienne. Cah Prothèse 2002;117:43-55.

[22] Laplanche Olivier. Evolution du guide incisif :phylogénèse ou adaptation fonctionnelle mémoire d'attestation universitaire: concepts généraux et champs d'applications de l'Anthropologie Biologique Marseille 1997.

[23] Lautrou A, Servières F. Analyse critique de la conception occluso fonctionnelle de D'Amico: données comparatives. Les cahiers de Prothèse 197:13:59-80. 
[24] Lee RL. Anterior guidance in: “Advance in occlusion” Lundeen HC. et Gibbs C. Boston John Wright PSG Inc. edit 1982.

[25] Linder-Aronson S. Die Wirkung der Atemfunktion auf das Kauorgan Internat. Kieferorth Fortbildungswoche Bad Gastein 1979.

[26] Lundeen HC, Gibbs CH. The function of teeth. The physiology of mandibular function related to occlusal form and esthetics. USA: L and G Publishers LLC; 2005.

[27] Mac Horris WH. The importance of anterior teeth. J Gnathol $1982 ; 1(1)$.

[28] Ogawa M, Ogawa T, Koyano K, Suetsugu T. Effect of altered canine guidance on condylar movement during laterotrusion. Int J Primatol 1998;11:139-44.

[29] Okano N, Baba K, Igarashi Y. Influence of altered occlusal guidance on masticatory muscle activity during clenching. J Oral Rehabil 2007;34(9):679-84.

[30] Okeson JP. Management of Temporomandibular Disorders and Occlusion 4th ed. Mosby: St Louis; 1998.

[31] Orthlieb JD, Laplanche O, Preckel EB. La fonction occlusale et ses dysfonctionnements. Réalités Cliniques 1997;7:131-46.
[32] Preston B. Johannesburg. Internationale Beiträge zur Kieferthopädie Quintessenz Verlag 1986;159-74.

[33] Slavicek R. Les principes de l'occlusion. Rev Franç d'Orthopédie Dento Faciale 1983;17:449-90; et 533-43.

[34] Smith BH, Garn SM, Hunter WS. Secular trends in face size. Angle Orthod 1986;56(3):196-204.

[35] Van der Linde PGM. Theoretische und praktische Aspêckte des Zahnengstandes im mensschlichen GebiB Inf Orthod Kieferorthop 1976;7:57-80.

[36] Vyslozil O, Jonke E. Kritscner Etude comparative orthodontique et anthropométrique de crânes humains de 100 ans et soldats de l'armée fédérale autrichienne. Rev Orthop Dento Faciale 1995;29:75-103.

[37] Vyslozil O. Weitchteileinflub auf die GebiBentwicklung. Vortrag Internat. Kieferorth Fortbildungswoche Bad Gastein, 1979.

[38] Williamson EH, Lundquist DO. Anterior guidance: its effect on electromyographic activity of the temporal and masseter muscles. J Prosthet Dent 1983;49(6):816.

[39] Société française d'orthopédie dento faciale Rapport annuel Les incisives: position céphalométrique et fonction biomécanique 1994;65. 